\title{
LAS DISTORSIONES DE LA LITERALIDAD EN EL RECURSO \\ A LAS FUENTES DE LA HISTORIA EN EL QUIJOTE. LA PARÁFRASIS IMPOSIBLE
}

1. Dice Daniel Pennac que para reconciliarse con la lectura hay que concebirla como un regalo, sustrayéndose a todo aquello que no se derive de la gratuidad inherente al placer de leer. Esto implica asumir la única condición de «no pedir nada a cambio. Absolutamente nada. No alzar ninguna muralla de conocimientos preliminares alrededor del libro. No plantear la más mínima pregunta. No encargar el más mínimo trabajo. No añadir ni una palabra a las de las páginas leídas. Ni juicio de valor, ni explicación de vocabulario, ni análisis de texto, ni indicación biográfica... Prohibirse por completo 'hablar de'» ${ }^{1}$.

$\mathrm{Al}$ convertir el texto en un problema y el acceso al texto en una búsqueda de soluciones, la lectura especializada que practica el cervantismo parece alejarse de esta propuesta en la que se reivindica un acto de comunión tan generoso y perfecto en sí mismo como es el diálogo íntimo entre el lector y el libro. Por lo que respecta al Quijote, sin embargo, una buena parte del placer de la lectura deviene de aceptar naturalmente el juego de la escritura de la obra, entendido como una estrategia de creación donde el descuido se atreve a penetrar por los resquicios que se abren ocasionalmente. El lector se siente seducido por la novela cuando acepta con mayor complicidad y se plantea con menor prejucio intelectual la pretensión de complejidad que informa la escritura de la historia y las circunstancias que la condicionan. El cervantista, que no es más que un lector informado (y en no pocas ocasiones, reconozcámoslo, un lector deformado), se deja llevar en efecto por los estímulos que

1 Danniel Pennac, Como una novela. Barcelona, Anagrama, 1993, p. 123. 
suscitan el placer de la lectura, pero convierte esa pretensión de complejidad en otro estímulo, no menos placentero por más intelectual.

2. Desde el momento en que entramos en el juego que define tal pretensión de complejidad tenemos que aceptar el Quijote como una cadena de lecturas: la historia de Don Quijote de la Mancha es principalmente escrita por un historiador, Cide Hamete Benengeli, que con su tarea de cronista, y por lo tanto de lector de fuentes escritas $^{2}$, ha superado en su historia una buena parte de las fuentes indefinidas, pero no su totalidad. Lo que leemos nosotros (lo que aceptamos estar leyendo), lectores del Quijote, es la paráfrasis, y por lo tanto relectura, que practica el segundo autor de la traducción de la historia original que propone el intérprete - no olvidemos la frecuente marca textual recordatoria de la paráfrasis «dice la historia»- y que como traducción supone en fin una nueva relectura. O sea, que leemos la lectura que hace el segundo autor de la lectura que hace el intérprete de la lectura - entendiendo la investigación histórica como lectura lato sensu- que hace Cide Hamete Benengeli. La literalidad sólo se sustenta en la superficie textual del Ingenioso hidalgo Don Quijote de la Mancha escrito por Miguel de Cervantes Saavedra, porque todo lo que por vía de recurso subyace a esta superficie nos sitúa ante un ejemplo logradísimo de transgresión de la literalidad, toda vez que, por una parte, el segundo autor no se limita a parafrasear la traducción de la historia, y por otra, el intérprete va más allá de su deber de transcribirla ad pedem litterae añadiendo sus explicaciones y decidiendo lo que conviene o no traducir. En fin, no sólo leemos una lectura de lecturas, sino que además hemos de aceptar la distorsión de la literalidad, lo que nos convierte en conocedores imperfectos de una historia transmitida con imprecisiones cometidas tanto por exceso como por defecto, teniendo en cuenta, desde luego, que la mayor perfección en el respeto a la literalidad (el recurso de la pretensión de literalidad, se entiende) está en los diálogos de los personajes.

3. Acaso deberíamos entender también que todo lo que leemos en los ocho primeros capítulos es igualmente una paráfrasis practicada por el segundo autor, pero no hay ninguna alusión a ninguna fuente definida, a diferencia de lo que ocurre en I, 9, en donde conocemos el nombre de la historia y el nombre del primer autor. Así pues, ahora nos interesa la paráfrasis sobre todo en tanto re-

2 «En este punto y término deja pendiente el autor desta historia esta batalla, disculpándose que no halló más escrito, destas hazañas de don Quijote». MIGUEL DE CERVANTES, El ingenioso hidalgo don Quijote de la Mancha, I, 8. Empleamos la edición de MARTín DE RIQuer. Barcelona, Planeta, 1980. 
curso explícito a la luz de la estrategia de la creación de la obra, y no como recurso inferido a posteriori por lo que respecta a los capítulos que definen la «primera parte» del Quijote de 1605. Y sabemos - jugamos a saber- que estamos ante una paráfrasis, y no ante la transcripción literal de la Historia de don Quijote de la Mancha, escrita por Cide Hamete Benengeli, historiador arábigo, porque a pesar de lo que puede prometer la frase "comenzaba desta manera» la literalidad queda transgredida, entre otras manifestaciones, por las frecuentes intervenciones del segundo autor y del traductor. Así, en el comienzo del capítulo II, 10, tras explicarnos el temor de Cide Hamete Benengeli a no ser creído por lo disparatado del comportamiento del protagonista, el segundo autor nos transmite, con los comentarios oportunos, la opción que adopta el primer autor al respecto, y vierte inmediatamente después su propia opinión acerca de la actitud de Benengeli ante su propia historia:

\footnotetext{
Llegando el autor desta grande historia a contar lo que en este capítulo cuenta, dice que quisiera pasarle en silencio, temeroso de que no había de ser creído, porque las locuras de don Quijote llegaron aquí al término y raya de las mayores que pueden imaginarse, y aún pasaron dos tiros de ballesta más allá de las mayores. Finalmente, aunque con este miedo y recelo, las escribió de la misma manera que él las hizo, sin añadir ni quitar a la historia un átomo de la verdad, sin dársele nada por las objeciones que podían ponerle de mentiroso. Y tuvo razón, porque la verdad adelgaza y no quiebra, y siempre anda sobre la mentira como el aceite sobre el agua.
}

También es el segundo autor, narrador de narradores, quien nos transmite parafrásticamente las opiniones del traductor sobre determinados aspectos de la historia original. Es el caso del comienzo del capítulo II, 27, donde el intérprete explica el verdadero sentido de determinado detalle textual que refleja la literalidad de la fuente original porque no parece ser coherente con la fe religiosa de Cide Hamete Benengeli:

Entra Cide Hamete, coronista desta grande historia, con estas palabras en este capítulo: "Juro como católico cristiano...»; a lo que su traductor dice que el jurar Cide Hamete como católico cristiano, siendo él moro, como sin duda lo era, no quiso decir otra cosa sino que, así como el católico cristiano cuando jura, jura, o debe jurar, verdad, y decirla en lo que dijere, así él la decía, como si jurara como cristiano, en lo que quería escribir de don Quijote...

O el fragmento del capítulo II, 18 en el que el intérprete no explica la literalidad, sino que interviene en ella transgrediéndola, curiosamente en aras de la coherencia con el interés de los objetos centrales de la historia: 
Aquí pinta el autor todas las circunstancias de la casa de don Diego, pintándonos en ella lo que contiene una casa de un caballero labrador y rico; pero al traductor desta historia le pareció pasar estas y otras semejantes menudencias en silencio, porque no venían bien con el propósito principal de la historia.

O lo que es lo mismo: que la paráfrasis, en su pretensión más fiel, en su estado más puro, es una tarea imposible, porque el intérprete se siente en el derecho de mutilar la literalidad en virtud de lo que Alan S. Trueblood denomina criterio de «selección artística» ${ }^{3}$. El mismo criterio de selección, basado en el decoro, anima a Cide Hamete Benengeli a descartar de su historia determinados capítulos impertinentes, como leemos en un fragmento del capítulo II, 12 que desde luego no tiene desperdicio:

[La amistad del rucio y de Rocinante] fue tan única y tan trabada, que hay fama, por tradición de padres a hijos, que el autor desta verdadera historia hizo particulares capítulos della; mas que, por guardar la decencia y decoro que a tan heroica historia se debe, no los puso en ella, puesto que algunas veces se descuida deste su prosupuesto, y escribe que, así como las dos bestias se juntaban, acudían a rascarse el uno al otro (...)

Digo que dicen que dejó el autor escrito que los había comparado en la amistad a la que tuvieron Niso y Euríalo, y Pílades y Orestes (...)

$Y$ no le parezca a alguno que anduvo el autor algo fuera de camino en haber comparado la amistad destos animales a la de los hombres, que de las bestias han recebido muchos advertimentos los hombres y aprendido muchas cosas de importancia....

O sea, que una vez más la paráfrasis trasciende las fronteras de la fuente histórica principal, escrita por Cide Hamete Benengeli, y afecta a la transmisión colateral que suponen las fuentes indefinidas, de las que toma elementos que se incorporan a eso que hemos dado en llamar texto final o superficie textual, a la que igualmente pertenecen, sin embargo, elementos presuntamente desestimables en un principio y finalmente incorporados al texto de la historia. En la fórmula de encaje "digo que dicen que dejó el autor escrito", no por casualidad forzada, entendemos el guiño de la construcción de la novela, según el cual aceptamos que el segundo autor es el gran arquitecto de la transmisión de la historia, procurando la trabazón de los datos que pertenecen a ella independientemente de la naturaleza de la fuente a la que se adscriban. Por otra parte, hay que

3 Cfr. Alan Trueblood, «Sobre la selección artística en el Quijote: '...lo que ha dejado de escribir' (II, 44)», Nueva Revista de Filología Hispánica, núm. X, 1956, pp. 44-50. Para la relación de este recurso con los libros de caballerías vid. SANTIAGO A. LÓPEZ NAVIA, La ficción autorial en el Quijote y en sus continuaciones e imitaciones. Madrid, Universidad Europea de Madrid-CEES Ediciones, 1996, pp. 119120 , n. 66. 
tener en cuenta la propia opinión del narrador sobre los criterios literarios y el uso de los recursos que despliega el primer autor, opinión que incrementa la superficie textual a costa, una vez más, de superar los límites de la literalidad.

El criterio de selección no afecta, sin embargo, a otros aspectos igualmente impertinentes para el "propósito principal de la historia» como el que conocemos por la paráfrasis del segundo autor en II, 48, desde el momento en que se incorpora al «texto final» - esa superficie textual que supone la literalidad incuestionable más allá de la aceptación del juego- algo tan impropio del texto literal de la historia original como la actitud ahora morbosa del primer autor en relación con el comportamiento de los personajes:

Aquí hace Cide Hamete un paréntesis, y dice que por Mahoma que diera, por ver a los dos así asidos y trabados desde la puerta al lecho, la mejor almalafa de dos que tenía.

El fragmento anterior demuestra que también Benengeli incorpora al texto de su historia elementos espurios que no forman parte de la historia misma, sino de su actitud ante los hechos reflejados en ella. O sea, que la literalidad queda transgredida tanto por defecto como por exceso, nueva muestra de la imposibilidad de la paráfrasis perfecta entendida como una pretensión de fidelidad - temática, que no, evidentemente, formal- a la historia. Mucho más complejo resulta el enfrentamiento con un momento de análisis de la actitud de quienes acceden a la historia original tan cumplidamente enrevesado como el comienzo del capítulo II, 44, en el que el juego de la paráfrasis no resiste los grandísimos problemas que plantea el encaje casi imposible de las voces de la narración ${ }^{4}$.

4. El texto "final»-entiéndase la intención del adjetivo- al que accedemos los lectores es el resultado de incrementar la transcripción parafrástica de la historia original a cargo del segundo autor con las intervenciones del segundo autor y el traductor y con las circunstancias propias de lo que yo denomino «historia del texto" o "historia de la historia» ${ }^{5}$, que se deriva de los sucesos protagonizados por el segundo autor en el proceso de indagación que le conducen a sus fuentes. Claro que las informaciones de esta dimensión de la historia no definen una correferencia recursiva válida en todo el Quijote, lo cual nos invita a reflexionar sobre la coherencia de los elementos literarios puestos en funcionamiento por Cervantes. Así, por ejemplo, en el primer capítulo del Quijote de 1615 el narrador comienza su paráfrasis haciendo mención explícita a la «se-

4 Cfr. LóPez NAVIA, op. cit., pp. 116-121.

5 Cfr. LÓPEZ NAVIA, op. cit., p. 92. 
gunda parte desta historia» sin brindar información alguna a los lectores acerca de la recuperación del hilo perdido en el capítulo I, 52, salvo que se nos invite a inferir que estamos accediendo a la transcripción parafrástica de la continuación natural, peripecias aparte, de la fuente histórica que conocemos desde el capítulo I, 9. Nada parece forzarnos a optar por una solución distinta a la que entraña esta forma de lectio facilior, salvo que deseemos aventurarnos a extraer conclusiones mucho más amplias que las premisas allí donde Cervantes acaso ha pretendido obviar toda complicación.

Sea como sea, la novela de Cervantes exige que aceptemos el juego que consiste en transcribir un texto, rara vez literalmente, y leer al mismo tiempo las opiniones y la narración de las peripecias de quienes acceden al texto de la presunta historia original. De este incremento textual forman parte, desde luego, los fragmentos laudatorios en los que el narrador encomia las cualidades del primer autor. Tenemos un buen ejemplo en el capítulo I, 16:

Fuera de que Cide Hamete fue historiador muy puntual y muy curioso en todas sus cosas, y échase bien de ver, pues las que quedan referidas, con ser tan mínimas y rateras, no las quiso pasar en silencio; de donde podrán tomar ejemplo los historiadores graves.

Y otro igualmente significativo en el comienzo del capítulo II, 40:

\footnotetext{
Real y verdaderamente, todos los que gustan de semejantes historias como ésta deben mostrarse agradecidos a Cide Hamete, su autor primero, por la curiosidad que tuvo en contarnos las semínimas della, sin dejar cosa, por menuda que fuese, que no la sacase a luz distintamente. Pinta los pensamientos, descubre las imaginaciones, responde a las tácitas, aclara las dudas, resuelve los argumentos; finalmente, los átomos del más curioso deseo manifiesta.
}

También debe entenderse como un ejercicio de paráfrasis que trasciende los límites naturales de la historia - y por tanto cualquier pretensión de literalidad- el comienzo del capítulo II, 27, en el que el narrador no se limita a parafrasear la historia traducida, en alternancia con un breve detalle literal de la fuente original, sino que también nos proporciona la paráfrasis de las explicaciones aducidas por el traductor.

Esto implica que no importa tanto la literalidad -la literalidad pretendida, se entiende-, como la adecuada comprensión de la literalidad, o lo que es lo mismo, que llegan a importar más las anécdotas que afectan a la fuente original que la fuente original misma, y como la paráfrasis es la fórmula de transmisión predominante en la intervención del segundo autor, en algunas ocasio- 
nes parece importar más la paráfrasis de la historia que la historia como tal. En este mismo orden de cosas, resulta de singular interés comprobar de qué manera la pretensión de literalidad, comunicada al lector mediante el recurso a la paráfrasis, refleja sin embargo la imprecisión de la fuente literal misma, como ocurre cuando el segundo autor nos dice que Cide Hamete Benengeli «no guarda la puntualidad(...) que en otras cosas suele» al no definir con nitidez el tipo de árbol —encinas o alcornoques, alcornoques o hayasal lado del cual se desarrollan algunas acciones en los capítulos II, 60 y II, 68 o al no especificar si las labradoras que Sancho Panza hace pasar por Dulcinea y sus damas en II, 10 venían a lomos de pollinos o pollinas. Estos alardes lúdicos dan mucho de sí, desde luego, más por las ampliaciones que aporta la paráfrasis que por la historia original de Benengeli.

5. Resulta muy significativo que la pretensión de literalidad no se transgreda precisamente en determinados microtextos escritos "al margen de la historia», que el segundo autor prefiere brindar al lector a partir de la traduccción exacta. Este es el efecto de transcribir textualmente la anotación del capítulo I, 9 en la que leemos que «esta Dulcinea del Toboso, tantas veces en esta historia referida, dicen que tuvo la mejor mano para salar puercos que otra mujer de toda la Mancha». Teniendo en cuenta la frecuencia de la marca correspondiente a la fuente indefinida «dicen» a lo largo de toda la transmisión de la historia, no hay ninguna razón especial para que le podamos atribuir a Cide Hamete Benengeli esta anotación marginal, por la misma razón que tampoco hay ninguna razón especial para que no se la podamos atribuir. No es esto, sin embargo, lo que queremos destacar, sino el hecho de que esa anotación marginal, que no nos llega mediante paráfrasis alguna, nos aporta precisamente la información acaso más precisa que encontramos sobre Dulcinea del Toboso en toda la novela. Lo mismo cabe observar sobre la nota escrita en esta ocasión por Cide Hamete Benengeli al margen del capítulo de la aventura de Montesinos - de la que, curiosamente, se nos da cuenta en el capítulo siguiente-, transcrita literalmente por el traductor, en la que el autor desplaza sobre el lector -recuérdese el capítulo II, 24- la responsabilidad de juzgar sobre la veracidad de las aventuras narradas por don Quijote. Este hecho no puede resultar más revelador, porque es el autor, a través de una manifestación marginal de literalidad, el que introduce dudas sobre la veracidad que hay en la pretensión de literalidad con la que se recoge el viaje imaginario narrado por don Quijote. O sea, que una cosa es la literalidad y otra la verdad; una cosa es el texto y otra los límites morales que plantea asumir el texto. 
6. El juego de la paráfrasis adquiere un especial interés cuando entra en relación directa con lo que debemos entender como estructura de la historia original. Así, en el final del capítulo I, 27, que es el último de la "Cuarta parte del ingenioso hidalgo don Quijote de la Mancha», la paráfrasis se ajusta a la estructuración del relato propuesta por Benengeli:

\footnotetext{
Aquí dio fin Cardenio a su larga plática y tan desdichada como amorosa historia; y al tiempo que el cura se prevenía para decirle algunas razones de consuelo, le suspendió una voz que llegó a sus oídos, que en lastimados acentos oyeron lo que se dirá en la cuarta parte desta narración, que en este punto dio fin a la tercera el sabio y atentado historiador Cide Hamete Benengeli.
}

Quizá no debamos entender tan claramente en el mismo sentido una transición como la que se da entre los capítulos 21 y 22 de la primera parte. No concebimos ninguna duda, sin embargo, acerca del título del capítulo II, 28 ( De cosas que dice Benengeli que las sabrá quien le leyere, si las lee con atención»), que nos lleva a entender que el segundo autor no respeta ni la estructura original ni la literalidad de los capítulos de la fuente original desde el momento en que parece evidente que es él quien le pone título por lo menos a alguno de los capítulos. Desde luego, parece muy claro que el título de este capítulo no podría ser clasificado fácilmente como «original», porque es un ejemplo palmario de título amplio por mor de la naturaleza lúdica de su imprecisión. De la misma manera, algunos incrementos textuales atribuibles al segundo autor no parecen ser perfectamente parafrásticos, sino que ocupan - parecen ocupar- un lugar estratégico de limitación estructural de las fronteras del relato al final de un capítulo. Es la interpretación que proponemos, por ejemplo, para el final del capítulo II, 20, donde se nos anticipa «lo que es fuerza se diga adelante», para el final del capítulo II, 31, donde se promete una respuesta que "capítulo por sí merece», y para el final del capítulo II, 47, donde se nos anuncia «lo que Cide Hamete promete de contar». Con el mismo valor de enlace entre unidades narrativas, pero con un mayor ánimo de captación de interés, debemos entender el final del capítulo II, 33, en el que se nos prometen «las mejores aventuras que en esta grande historia se contienen».

7. La proyección del segundo autor sobre la historia que probablemente implica el uso de la primera persona en medio de la narración del manteo de Sancho en I, 17 ( «...si la cólera le dejara, tengo para mí que se riera») —suponiendo, claro está, que esta primera persona forme parte de la estrategia parafrástica y no de la literalidad del texto de la fuente original- es una nueva muestra 
de la construcción variada y compleja de la superficie textual, igual, y en la misma suposición, que el eje dialógico retórico que se establece entre el narrador-segundo autor y el lector a la hora de mostrar en el capítulo II, 44 la transición narrativa que se practica al pasar de Sancho a don Quijote como objetos de la narración:

Deja, lector amable, ir en paz y en hora buena al buen Sancho, y espera dos fanegas de risa, que te ha de causar el saber cómo se portó en su cargo, y, en tanto, atiende a saber lo que le pasó a su amo aquella noche; que si con ello no rieres, por lo menos desplegarás los labios con risa de jimia, porque los sucesos de don Quijote, o se han de celebrar con admiración, o con risa.

Es el mismo problema que se puede apreciar al comienzo del capítulo siguiente, donde el eje dialógico retórico, de corte apostrófico, invita a dudar sobre la naturaleza textual, literal o parafrástica - suponemos, por coherencia, que esta última- del primer párrafo:

¡Oh perpetuo descubridor de los antípodas (...) A ti digo, ¡oh sol, con cuya ayuda el hombre engendra al hombre!; a ti digo que me favorezcas, y alumbres la escuridad de mi ingenio, para que pueda discurrir por sus puntos en la narración del gobierno del gran Sancho Panza; que sin ti, yo me siento tibio, desmazalado y confuso.

8. La paráfrasis, por fin, descubre propuestas a todas luces contradictorias, bien en su propio contexto reducido o en el contexto amplio de la obra. No de otra manera debemos entender el fragmento del capítulo I, 16 en el que el narrador encarece el respeto que profesa Maritornes a la palabra dada:

Y cuéntase desta buena moza que jamás dio semejantes palabras que no las cumpliese, aunque las diese en un monte y sin testigo alguno.

Aparte de la paradoja que implica preguntarse cómo se puede estar seguro del cumplimiento de una promesa sin asistir presencialmente a su formulación, el verbum dicendi de la oración principal de esta secuencia, expresado de forma impersonal, nos invita a plantearnos la naturaleza de la fuente parafraseada por el segundo autor, dando lugar a dos posibles interpretaciones: una, que "cuéntase» equivale a "dicen», e implica, por lo tanto, que se incorpora a la transcripción de la historia un resultado al que se ha accedido, como en otras ocasiones, mediante el seguimiento de una fuente indefinida; otra, que lo que se cuenta, se cuenta en la historia escrita por Cide Hamete Benengeli, que es una fuente definida, lo que no quiere decir, ya lo sabemos, que sea una fuente precisa. 
El estudio del contexto amplio del Quijote permite captar otras contradicciones que tienen que ver con el grado de perfección que caracteriza al conocimiento que tiene el historiador de los protagonistas de su historia. En el capítulo II, 34 leemos la clave que más claramente apunta en toda la obra al conocimiento directo, empírico, que tiene el autor de quienes son objeto de su tarea como cronista:

y dice Cide Hamete que pocas veces vio a Sancho Panza sin ver al rucio, ni al rucio sin ver a Sancho: tal era la amistad y buena fe que entre los dos se guardaban.

Así como en el anterior fragmento aceptamos una paráfrasis simple, en el siguiente párrafo del capítulo II, 48 asistimos a la transcripción en estilo indirecto de una intervención parentética del primer autor:

\footnotetext{
Aquí hace Cide Hamete un paréntesis, y dice que por Mahoma que diera, por ver ir a los dos así asidos y trabados desde la puerta al lecho, la mejor almalafa de dos que tenía.
}

A diferencia del fragmento antes transcrito, gracias al cual sabemos que Benengeli vio, la proyección del historiador árabe sobre la intimidad de quienes son objeto de su acción histórica nos permite deducir con toda claridad que en esta ocasión no vio. ¿Debemos aceptar que a Cervantes le interesa sugerir que Cide Hamete accede a un conocimiento limitado e imperfecto de los protagonistas de su historia? ¿Desea sugerir Cervantes que el historiador siguió personalmente los pasos de quienes protagonizan su historia, conviviendo con ellos? ¿Debemos entender que se está practicando un uso consciente y estratégico de fórmulas equívocas que se engranan en una correferencia aplazada? ¿O debemos asumir, sin más, que estamos leyendo una formulación natural, espontánea y descuidada de la obra? Las posibles respuestas para estas preguntas, acaso preguntas sin respuesta, son las que nos permiten diferenciar la lectura de los problemas de la novela de la lectura problemática de la novela. En el primer caso, los problemas del texto son el objeto de la lectura; en el segundo, la actitud problemática es el principal criterio de la lectura.

El planteamiento imposible de las aporías de Zenón de Elea demostró el ingenio que podía derrocharse para crear problemas imposibles en virtud de la paradoja. Frente a ellas, el pastor luterano Johann Peter Hebel ${ }^{6}$ se esforzó por plantear a los lectores de su

6 Cfr. Cofrecillo de joyas del amigo de la casa renano, recientemente editado por Alba Editorial (Barcelona, 1998), traducido por Anton Dietrich. 
almanaque ingeniosos problemas reales y de solución posible. En medio de los dos, Cervantes supo crear problemas reales de solución no siempre posible, acaso porque no los concibió para ser resueltos sino para ser considerados permanentemente como una estimulante invitación a la perplejidad, a la duda y al juego. Si en las trampas aporéticas de Zenón hemos llegado a descubrir que lo de menos era el problema en virtud de su falsa complejidad, cuya aceptación era el resultado de un acuerdo entre el creador del problema y quien se prestaba a resolverlo, y si en los problemas del pastor Hebel lo realmente importante era el ingenio de quien aportaba una solución brillante a un problema cuya complejidad no devenía de aceptar ninguna convención sino de enfrentarse inteligentemente a sus incógnitas, quizá tengamos que aceptar alguna vez que en el análisis de los problemas que plantea el texto del Quijote lo que menos importa - por lo menos, a buen seguro, lo que menos importaba a Cervantes- son las soluciones.

SANTIAGo LóPEZ NAVIA

Universidad Internacional SEK

(Segovia, España) 